\title{
Exercise Training Restores Hypertension- Induced Changes in the Elastic Tissue of the Thoracic Aorta
}

\author{
Maria Tereza Jordão a,b Fernando V.L. Ladd ${ }^{c}$ Antonio Augusto Coppi ${ }^{c}$ \\ Renato P. Chopard ${ }^{\mathrm{b}}$ Lisete C. Michelini ${ }^{\mathrm{a}}$ \\ Departments of ${ }^{\mathrm{a}}$ Physiology and Biophysics, and ${ }^{\mathrm{b}}$ Anatomy, Institute of Biomedical Sciences, and ${ }^{\mathrm{c}}$ Department of \\ Surgery, Laboratory of Stochastic Stereology and Chemical Anatomy, College of Veterinary Medicine, University of \\ São Paulo, São Paulo, Brazil
}

\section{Key Words}

Thoracic aorta - Vascular remodelling $\cdot$ Elastic fibres •

Smooth muscle cells · Collagen · Gene expression •

Spontaneously hypertensive rats $\cdot$ Exercise training

\begin{abstract}
Background/Aims: Pharmacological antihypertensive therapies decrease both wall hypertrophy and collagen, but are unable to diminish the elastic content in the thoracic aorta. We investigated the effects of exercise training on aortic structure and function. Methods: Spontaneously hypertensive rats (SHR) and normotensive rats (WKY), submitted to low-intensity training $(\mathrm{T})$ or kept sedentary $(\mathrm{S})$, were subjected to haemodynamic analyses. The thoracic aorta was processed for real-time PCR, light (morphometric/stereological evaluations) and electron microscopy. Results: $\mathrm{SHR}_{S}$ versus WKY $Y_{S}$ exhibited a higher heart rate, pressure and pulse pressure, increased $\alpha$-actin, elastin and collagen mRNA expression, augmented wall volume and cross-sectional area (marked elastin/collagen content). In the SHR, training reduced pressure and heart rate, with slight reduction in pulse pressure. $\mathrm{SHR}_{\mathrm{T}}$ aortas exhibited small morphometric changes, reduced $\alpha$-actin, elastin and collagen mRNA expression,
\end{abstract}

normalization of increased elastic content, reduction in collagen/connective tissue and a decrease in smooth muscle cell volume ( $p<0.05$ for all comparisons). SHR aortas showed improved circumferential orientation of smooth muscle cells and prevention of rupture/duplication of internal elastic lamina. No effects were observed in trained WKY aortas. Conclusions: Training effectively corrects elastic, collagen and smooth muscle content in SHR aortas. These changes, by reducing aortic pulsatility, facilitate a buffering function and reduce the cardiovascular risk.

Copyright $\odot 2011$ S. Karger AG, Basel

\section{Introduction}

The thoracic aorta, besides supplying blood to peripheral tissues and organs (conduit function), has the important function to dampen pressure oscillations resulting from intermittent ventricular ejection (cushioning function), thus coupling the heart function with the cardiovascular system $[1,2]$. Like the other arteries, the thoracic aorta is composed by layers of vascular smooth muscle cells and extracellular matrix (elastic and connective tissue, composed mainly by elastin and collagen, respec-

\section{KARGER}

Fax +41613061234 E-Mail karger@karger.ch www.karger.com
(C) 2011 S. Karger AG, Basel

$1018-1172 / 11 / 0486-0513 \$ 38.00 / 0$

Accessible online at:

www.karger.com/jvr
Dr. Lisete Compagno Michelini

Department of Physiology and Biophysics, Institute of Biomedical Sciences

Universidade de São Paulo, Av. Prof. Lineu Prestes, 1524

São Paulo, SP 05508-000 (Brazil)

Tel. +55 113091 7213,E-Mail michelin@usp.br 
tively), but different from distal arteries, elastin, arranged in elastic lamellas and fibres, is the dominant component being responsible for extensibility and resilience of the vessel [1-3]. The higher elastin/collagen ratio reduces aortic stiffness and minimizes pulsatility, thus improving the cushioning function of the thoracic aorta.

In both human and animal models, hypertension has been associated with structural remodelling (phenotypic switching of smooth muscle cells, increased collagen deposit with decreased elastin/collagen ratio, besides a defective elastin synthesis) $[3,4]$ and with mechanical changes in the aortic function (increased wall stiffness and pulsatility) [2], which reduces the buffering function of the large arteries and contributes to the end-organ damage in hypertension. Most studies have focused on the marked hypertension-induced increases in vascular collagen [4-6], but some have also assessed the effects of hypertension on elastic fibres, the main component of the thoracic aorta, showing significant increases in elastin in renal, Dahl salt-sensitive, deoxycorticosterone acetatesalt and spontaneous hypertension [3, 6-8]. Accumulated evidence also showed that pressure-induced elastogenesis yields abnormal elastic fibre formation [9] which, together with an increased collagen content, caused increased vessel stiffness. Due to both rapid accumulation and a very low turnover of elastin and collagen in the vascular wall [10], the risks and consequences of hypertension may persist for long periods of time.

Current antihypertensive therapies are intended not only to reduce pressure but also to reverse hypertensioninduced structural changes [11, 12]. Indeed, angiotensin receptor blockers, angiotensin-converting enzyme inhibitors, aldosterone antagonists and calcium channel blockers are known to decrease the media collagen content, but accumulation of elastin still persisted after pressure had been restored to near-normal levels $[6,13,14]$. On the other hand, a cross-sectional study from the Baltimore Longitudinal Study of Ageing [15] showed that an older man performing regular endurance training, a nonpharmacological antihypertensive therapy, exhibited decreased pulse wave velocity and a small carotid augmentation index, two important indexes characterizing a higher cushioning function of vessels [16]. In addition, previous studies from our laboratory $[17,18]$ have already demonstrated the ability of exercise training in remodelling heart, diaphragm and skeletal muscle arterioles in trained spontaneously hypertensive rats $\left(\mathrm{SHR}_{\mathrm{T}}\right)$ : low-intensity aerobic training was able to reverse the altered vascular structure, normalizing the wall/lumen ratio of the arteriole, with significant positive correlations be- tween pressure fall and the wall/lumen ratio reduction of the arteriole and between pressure fall and hind limb resistance reduction $[17,18]$.

Taking into consideration the demonstrated efficacy of exercise training to remodel arteries/arterioles and our limited knowledge of antihypertensive therapy-induced changes in the structure and function of aortic elastic fibres, we sought to determine the effects of exercise training on cardiovascular parameters (functional data), on the structure and morphometry of the thoracic aorta (light and electronic microscopy) and on the structural changes of the aortic components (mRNA expression and protein distribution within the aortic wall) of normotensive rats (WKY) and SHR submitted to aerobic training or kept sedentary.

\section{Methods}

\section{Animal Protocols}

Male WKY and SHR aged 2 months were housed in plexiglas cages on a 12-hour light/12-hour dark cycle and allowed free access to food and water. Rats were initially pre-selected for their ability to walk on a treadmill (8-10 sessions at $0.4-0.8 \mathrm{~km} / \mathrm{h}, 0 \%$ grade, $10 \mathrm{~min}$ /day; Inbramed, KT-300). At week zero, before starting protocols, active rats were submitted to maximal exercise test (graded exercise on the treadmill, $0 \%$ grade, starting at $0.3 \mathrm{~km} / \mathrm{h}$ with increments of $0.3 \mathrm{~km} / \mathrm{h}$ every $3 \mathrm{~min}$ up to exhaustion) in order to determine maximal individual exercise capacities and to assign rats with equivalent capability to trained or sedentary groups. Low-intensity training was performed 5 days/week, $1 \mathrm{~h} /$ day over 3 months, as previously described [19-21]. Briefly, exercise intensity was increased progressively by a combination of time and speed to attain at the 2 nd to $3 \mathrm{rd}$ week $1 \mathrm{~h} /$ day and $50-$ $60 \%$ of maximal exercise capacity, as determined by the maximal exercise tests on the treadmill. Maximal exercise tests were repeated for each rat at the 6th and 12th week in order to adjust training intensity and to compare the efficacy of the training protocol, respectively. Rats submitted to the sedentary protocol were handled every day and submitted once a week to a short period of mild exercise (5-10 $\mathrm{min}, 0.4-0.8 \mathrm{~km} / \mathrm{h}, 0 \%$ grade). These protocols resulted in 4 groups of rats, sedentary WKY $\left(\mathrm{WKY}_{\mathrm{S}}\right)$, sedentary SHR $\left(\mathrm{SHR}_{\mathrm{S}}\right)$, trained WKY $\left(\mathrm{WKY}_{\mathrm{T}}\right)$ and trained $\mathrm{SHR}\left(\mathrm{SHR}_{\mathrm{T}}\right)$. All surgical procedures and protocols used conformed to the Ethical Principles in Animal Research of the Brazilian College of Animal Experimentation and were approved by the Institutional Animal Care and Use Committee.

Measurements at the Conscious State and Tissue Sampling

At the end of the training and sedentary protocols, rats were anaesthetized with a mixture of ketamine $(80 \mathrm{mg} / \mathrm{kg})$, xylazine $(12 \mathrm{mg} / \mathrm{kg})$ and acepromazine $(0.05 \mathrm{mg} / \mathrm{kg}), 0.4 \mathrm{ml} / \mathrm{kg}$ intraperitoneally, for implantation of an arterial catheter [made of 2 segments of vinyl tubing (Critchley): $2 \mathrm{~cm}$ of $0.28 / 0.61 \mathrm{~mm}$, heat merged with $4.5 \mathrm{~cm}$ of $0.50 / 1.50 \mathrm{~mm}$ inner/outer diameter] into the right carotid artery. The thicker (external) part of the catheter 
was tunneled subcutaneously, exteriorized at the back of the neck and fixed with a suture in the midscapular region. After a recovery period of $24-48 \mathrm{~h}$, the arterial catheter was connected to a Gould Statham P23XL transducer in an 8-channel recorder system (Gould, model 5900), and a variable period of time was allowed for the stabilization of cardiovascular parameters. Resting values of arterial pressure (AP, systolic, diastolic, mean and pulse pressure) and heart rate (HR, Biotach triggered by the pulse pressure) were then recorded continuously for 20-30 min (beat-tobeat record) in conscious unrestrained rats.

After functional measurements, rats were deeply anaesthetized (ketamine/xylazine/acepromazine, $0.8 \mathrm{ml} / \mathrm{kg}$ i.p.). Immediately after the respiratory arrest they were submitted to transcardiac perfusion with buffered saline $(100-150 \mathrm{ml}, 20-30 \mathrm{ml} / \mathrm{min}$, Daiger Pump, with the perfusion pressure kept in the same range as the mean AP recorded in the conscious animals). In 5 rats of each group the fresh thoracic aorta was dissected (from the aortic arch up to the diaphragm), removed, snap-frozen in liquid nitrogen and stored in a deep freezer for posterior reverse transcriptase (RT)-PCR analysis. Rats assigned to morphometric and stereological analyses (7-8/group) were, after buffered saline perfusion, perfused with $4 \%$ paraformaldehyde in $0.1 \mathrm{~mol} / \mathrm{l}$ phosphate buffer, $\mathrm{pH} 7.2,250-350 \mathrm{ml}$. The thoracic aorta $(20-22 \mathrm{~mm})$ was removed, cut into small rings (approximately $5 \mathrm{~mm}$ width) and post-fixed in the same fixative for $24 \mathrm{~h}$. In the rats assigned to ultrastructural analysis (2/group), saline perfusion was followed by perfusion with a modified solution of Karnovsky (2.5\% of glutaraldehyde plus $2 \%$ of paraformaldehyde in $0.01 \mathrm{M}$ phosphate buffer, $\mathrm{pH} 7.3,250-350 \mathrm{ml})$. The thoracic aorta was harvested, cut into 5-mm-thick pieces, and small longitudinal segments harbouring the vessel wall were obtained from upper, medium and lower aortic rings. These segments were immersed in Karnovsky solution for $2 \mathrm{~h}$.

\section{RT-PCR Analysis}

Total mRNA from the thoracic aorta was extracted using Trizol ${ }^{\circledR}$ according to the manufacturer's instructions. DNase I was used to digest DNA, thus obtaining pure mRNA prior to the $\mathrm{RT}$ reaction. mRNA integrity in each sample was verified by agarose gel electrophoresis. Total mRNA $(2 \mu \mathrm{g})$ was used for firststrand cDNA synthesis using SuperScript II (RNaseOUT was added for protection). In three pooled mRNA aliquots, RT was omitted to ensure the absence of DNA contaminants. Diluted RT samples (1:10) were submitted to real-time PCR amplification using Platinum ${ }^{\circledR}$ SYBR $^{\circledR}$ QPCR Supermix-UDG and specific oligonucleotides for $\alpha$-actin (forward, ATCCGATAGAACACGGCATC; reverse, CACGCGAAGCTCGTTATAGA; 83 bp), elastin (forward, CTGCCAAATATGGTGCTGCT; reverse, CCACCACCTGGGTAGATAGG; 115 bp), collagen I (forward, CGAGACCСTTCTCACTCCTG; reverse, GCATCCTTGGTTAGGGTCAA; $121 \mathrm{bp)}$ ) and collagen III (forward, GGGATCCAATGAGGGAGAAT; reverse, GGCCTTGCGTGTTTGATATT; 130 bp). $\beta$-Actin was used as an internal control (forward, AAGATTTGGCACCACACTTTCTACA; reverse, CGGTGAGCAGCACAGGGT; 69 bp). Real-time PCR reactions were performed, recorded and analysed using the Corbett Research System (Corbett Life Sciences, Sydney, Australia). The conditions for PCR were as follows: $95^{\circ} \mathrm{C}$ for $2 \mathrm{~min}$, then 40 cycles of $95^{\circ} \mathrm{C}$ for $15 \mathrm{~s}, 60^{\circ} \mathrm{C}$ for $1 \mathrm{~min}$, and $72^{\circ} \mathrm{C}$ for $15 \mathrm{~s}$. The specificity of the SYBR Green assay was confirmed by melting point analysis. Expression data were calculated from the cycle threshold (Ct) value using the $\Delta \Delta \mathrm{Ct}$ method for quantification [22]. Results, normalized by $\beta$-actin mRNA, were expressed as fold increase. All oligonucleotides and reagents used in this protocol were purchased from Invitrogen Co. (San Diego, Calif., USA).

\section{Morphological/Morphometric Evaluations}

Aortic rings were dehydrated in graded ethanol concentrations (70, 80, 90 and 100\%) and embedded in histological paraplast. The paraplast blocks were cut with a microtome $(5-\mu \mathrm{m}$ thick sections; Leica). Transverse sections were mounted on a glass slide and stained with the Weigert-haematoxylin technique. Three slides with 5 semi-serial (1 section every $25 \mu \mathrm{m}$ ) sections each, i.e. a total of 15 sections, were obtained from each sample. Morphological analysis conducted in transversal aortic sections with a light microscope (Nikon E1000, ×200 and $\times 400$ magnifications) permitted the identification of elastic lamellas/ fibrils (Weigert stain) and smooth muscle constituents (haematoxylin stain). Thoracic aorta images were acquired (colour video camera Nikon ACT-1 for DXM1200F) and digitized for offline morphometric analysis (Image Pro Plus 5.1 software). Analysis included the determination of inner $(\mathrm{Ai}=$ lumen $)$ and outer areas (Ao = whole area of the vessel), used for calculation of the inner and outer diameter of the thoracic aorta $(D=2 r$, where $r$ is the inner or the outer radius) and for the calculation of either the cross-sectional area $(\mathrm{CSA}=\mathrm{Ao}-\mathrm{Ai})$, wall thickness $(\delta=$ outer $r$ - inner $r$ ) and media-to-lumen ratio (media/lumen $=\delta$ / inner D).

\section{Stereological Estimations}

Section images (systematic uniform random sampling) were acquired using a DMR Leica microscope equipped with a HighEnd DP 72 Olympus digital camera and projected onto a computer monitor. Stereological analyses were performed using the new CAST Visiopharm Stereology System, version 3.6.5.0.

Volume of Thoracic Aorta. The volume of the thoracic aorta $\left(\mathrm{V}_{\mathrm{TA}}\right)$ was estimated by means of the Cavalieri principle [23]. Briefly, thoracic aorta paraplast-embedded blocks were exhaustively serially sectioned and every 5 th section (5- $\mu \mathrm{m}$-thick each) was sampled and measured for the cross-sectional area. Then,

$$
\mathrm{V}_{\mathrm{TA}}=\mathrm{T} \times \Sigma \mathrm{A}_{\mathrm{TA}},
$$

where $\mathrm{T}$ is the between-section distance $(50 \mu \mathrm{m})$ and $\Sigma \mathrm{A}_{\mathrm{TA}}$ is the sum of the delineated profile areas of the thoracic aorta. Profile areas were estimated from the numbers of randomly positioned test points hitting the whole reference space (points: about 151 in $\mathrm{WKY}_{\mathrm{S}}$ rats, about 138 in $\mathrm{WKY}_{\mathrm{T}}$ rats, about 161 in $\mathrm{SHR}_{\mathrm{S}}$ rats and about 158 in $\mathrm{SHR}_{\mathrm{T}}$ rats) and the area equivalent of a test point (the area associated with each test point $=90,813 \mu \mathrm{m}^{2}$ ). The mean volume shrinkage (observed coefficient of variation, $\mathrm{CV}_{\text {obs }}$ ) was estimated to be $23.8 \%(0.21)$ in $\mathrm{WKY}_{\mathrm{S}}, 22.6 \%(0.32)$ in $\mathrm{WKY}_{\mathrm{T}}, 23.2 \%$ $(0.23)$ in $\mathrm{SHR}_{\mathrm{S}}$ and $23.4 \%(0.26)$ in $\mathrm{SHR}_{\mathrm{T}}$ rats. Since betweengroup differences were not significant $(\mathrm{p}=0.50)$, correction for global shrinkage was not performed.

Volume Densities of Thoracic Aorta Compartments. The fractional volumes of thoracic aorta compartments - vascular smooth muscle nuclei, fibrillar elastic fibre, lamellar elastic fibre, total elastic fibre and connective tissue - were estimated by counting randomly positioned test points in the same sections used for 
Cavalieri's estimate of $\mathrm{V}_{\mathrm{TA}}$. A given compartmental volume density $\left(\mathrm{V}_{\mathrm{vCOMP}}\right)$ was therefore estimated as

$$
\mathrm{V}_{\mathrm{vCOMP}}=\Sigma \mathrm{P}_{\mathrm{COMP}} / \sum \mathrm{P}_{\mathrm{TA}},
$$

where $\Sigma \mathrm{P}_{\mathrm{COMP}}$ and $\Sigma \mathrm{P}_{\mathrm{TA}}$ represent the sums of points falling on the thoracic aorta compartment and entire thoracic aorta across all sections from a given thoracic aorta, respectively [24].

Total Volumes of Thoracic Aorta Compartments. The total volumes occupied by the thoracic aorta compartments $\left(\mathrm{V}_{\mathrm{COMP}}\right)$ were estimated indirectly by multiplying their fractional volumes $\left(\mathrm{V}_{\mathrm{vCOMP}}\right)$ by the thoracic aorta volume $\left(\mathrm{V}_{\mathrm{TA}}\right)$ [25].

Precision of Stereological Estimates. The precision of all stereological estimates was expressed as a coefficient of error, estimated as reported by Gundersen et al. [23].

\section{Transmission Electron Microscopy}

After the 2-hour post-fixation, segments of the thoracic aorta were washed in phosphate-buffered solution and post-fixed again in $2 \% \mathrm{O}_{\mathrm{S}} \mathrm{O}_{4}$ for $2 \mathrm{~h}$ at $4^{\circ} \mathrm{C}$. Vessels were stained en bloc with uranyl acetate (overnight), dehydrated in a graded series of ethanols $(60,70,80,90$ and 100\%) and embedded in Epon. Semi-thin sections (1- $\mu \mathrm{m}$ thick) were mounted on glass slides and stained with toluidine blue. Thin sections (60-nm thick) contrasted with uranyl acetate at $4 \%$ and with lead citrate at $0.4 \%$ were examined in a LEO906E electron microscope.

\section{Data Analysis and Statistics}

Two-way ANOVA (strain and condition) was used to compare treadmill performance, functional values, such as $\mathrm{HR}$, mean AP (MAP) and pulse pressure, morphometric parameters (cross-sectional area, wall thickness and media-to-lumen ratio) and mRNA expression data (logarithmic transforms), reported as means \pm SEM. Significant differences were further investigated by using Newman-Keuls as the post hoc test. Stereological data (non-parametric values) were expressed as group mean $\left(\mathrm{CV}_{\mathrm{obs}}\right)$, where $\mathrm{CV}_{\mathrm{obs}}$ represents the standard deviation of the mean divided by the group mean. Inter-group differences were assessed by general linear model-ANOVA, using Minitab statistical software, version 16. Fisher's test for multiple comparisons was used as the post hoc test. In both groups, correlation analysis (mRNA expression and stereological estimates $\times$ MAP changes) were performed by Pearson (parametric data) or Spearman (non-parametric data) tests. For all data, the level of significance was set at $\mathrm{p}<0.05$.

\section{Results}

\section{Efficacy of the Training Protocol}

Since the beginning of protocols, SHR exhibited a better performance on treadmill than age-matched WKY (147 \pm 7 vs. $105 \pm 7 \mathrm{~m}$, respectively, attained on the maximal exercise test at week zero; $\mathrm{p}<0.05)$. In both groups, significant increases in running distance were already observed at the 6th week of training; at the 12th week, the distance was on average 3.2 times greater than that of week zero $(\mathrm{p}<0.05)$. By the end of protocols, sed- entary groups exhibited no change (WKY) or slight decrease (SHR), while trained groups exhibited a robust increase in treadmill performance $(+264 \pm 12$ and $+279 \pm$ $33 \mathrm{~m}$, week 12 minus week zero, for $\mathrm{WKY}_{\mathrm{T}}$ and $\mathrm{SHR}_{\mathrm{T}}$, respectively, $\mathrm{p}<0.05$; fig. 1a). Importantly, exercise training equally improved the performance on treadmill in both $\mathrm{WKY}_{\mathrm{T}}$ and $\mathrm{SHR}_{\mathrm{T}}$ versus respective sedentary controls.

\section{Functional Data}

Direct measurement of AP and HR in conscious rats at rest showed that $\mathrm{SHR}_{\mathrm{S}}$ had higher basal values of MAP and HR $(172 \pm 1 \mathrm{~mm} \mathrm{Hg}$ and $386 \pm 9$ beats/min, respectively; fig. 1c, b) when compared to $\mathrm{WKY}_{\mathrm{S}}$. Pulse pressure was also significantly higher in the $\mathrm{SHR}_{S}$ group (vs. WKY ; fig. 1d). Trained rats showed significant resting bradycardia (HR reductions of 6 and $8 \%, \mathrm{WKY}_{\mathrm{T}}$ and $\mathrm{SHR}_{\mathrm{T}}$ vs. WKY $\mathrm{W}_{\mathrm{S}}$ and $\mathrm{SHR}_{\mathrm{S}}$, respectively; fig. $1 \mathrm{~b}$ ), but an MAP fall was only observed in the $\mathrm{SHR}_{\mathrm{T}}$ group (-5\% vs. $\mathrm{SHR}_{S}, \mathrm{p}<0.05$; fig. 1c). Training did not change the pulse pressure in either group (the slight decrease observed in the $\mathrm{SHR}_{\mathrm{T}}$ vs. $\mathrm{SHR}_{\mathrm{S}}$ did not attain significance; fig. 1d).

\section{Effects of Hypertension and Training on the}

Expression of $\alpha$-Actin, Elastin and Collagen $m R N A$

mRNA expression of all thoracic aorta components were significantly higher in SHR versus WKY ( $p<0.05$ for group factor): $\alpha$-actin mRNA was increased by 9 -fold (from $1.27 \pm 0.46$ to $11.39 \pm 3.51 \mathrm{AU}$; fig. 2a); elastin mRNA was increased by 6.3-fold (from $1.21 \pm 0.36$ to $7.59 \pm 2.29 \mathrm{AU}$; fig. $2 \mathrm{~b}$ ), while collagen I and III mRNA were increased by 11-fold on average (from $1.10 \pm 0.24$ to $13.72 \pm 5.88 \mathrm{AU}$ and from $1.24 \pm 0.38$ to $11.75 \pm 4.05$ $\mathrm{AU}$, respectively; fig. 2c, d). Interestingly, mRNA expressions of $\alpha$-actin, elastin and collagen I and III were completely normalized by training in the SHR group, with no significant changes in the WKY controls (fig. 2).

\section{Effects of Hypertension and Training on \\ Morphological, Morphometric and Stereological \\ Parameters}

Figure 3 illustrates and compares the aortic wall appearance in sedentary and trained WKY and SHR. In all groups, the aortic wall exhibited 7-8 elastic lamellas and many elastic fibrils that extended from the lamellas and permeated the smooth muscle cell layer. Notice the paler staining and the increased content of elastic fibres and fibrils in the $\mathrm{SHR}_{\mathrm{S}}$ when compared to the other groups. Interestingly, in the $\mathrm{SHR}_{\mathrm{T}}$, elastic fibres/fibrils are less ev- 
Fig. 1. Running distance gain in the 4 groups of rats at the end of sedentary and training protocols, showing the efficacy of training (a). Resting values of HR (b), MAP (c) and pulse pressure (d) in trained (T) and sedentary (S) WKY and SHR groups. $\mathrm{n}=12$ rats/group. ${ }^{\mathrm{a}} \mathrm{p}<0.05$ versus WKY; ${ }^{b} \mathrm{p}<0.05$ versus sedentary groups.

Fig. 2. RT-PCR studies showing the expression of $\alpha$-actin (a), elastin (b), collagen I (c) and collagen III mRNAs (d) in the thoracic aorta of sedentary (S) and trained (T) WKY and SHR groups. $\mathrm{n}=5$ rats/ group. ${ }^{a} \mathrm{p}<0.05$ versus WKY; ${ }^{\mathrm{b}} \mathrm{p}<0.05$ versus sedentary groups.
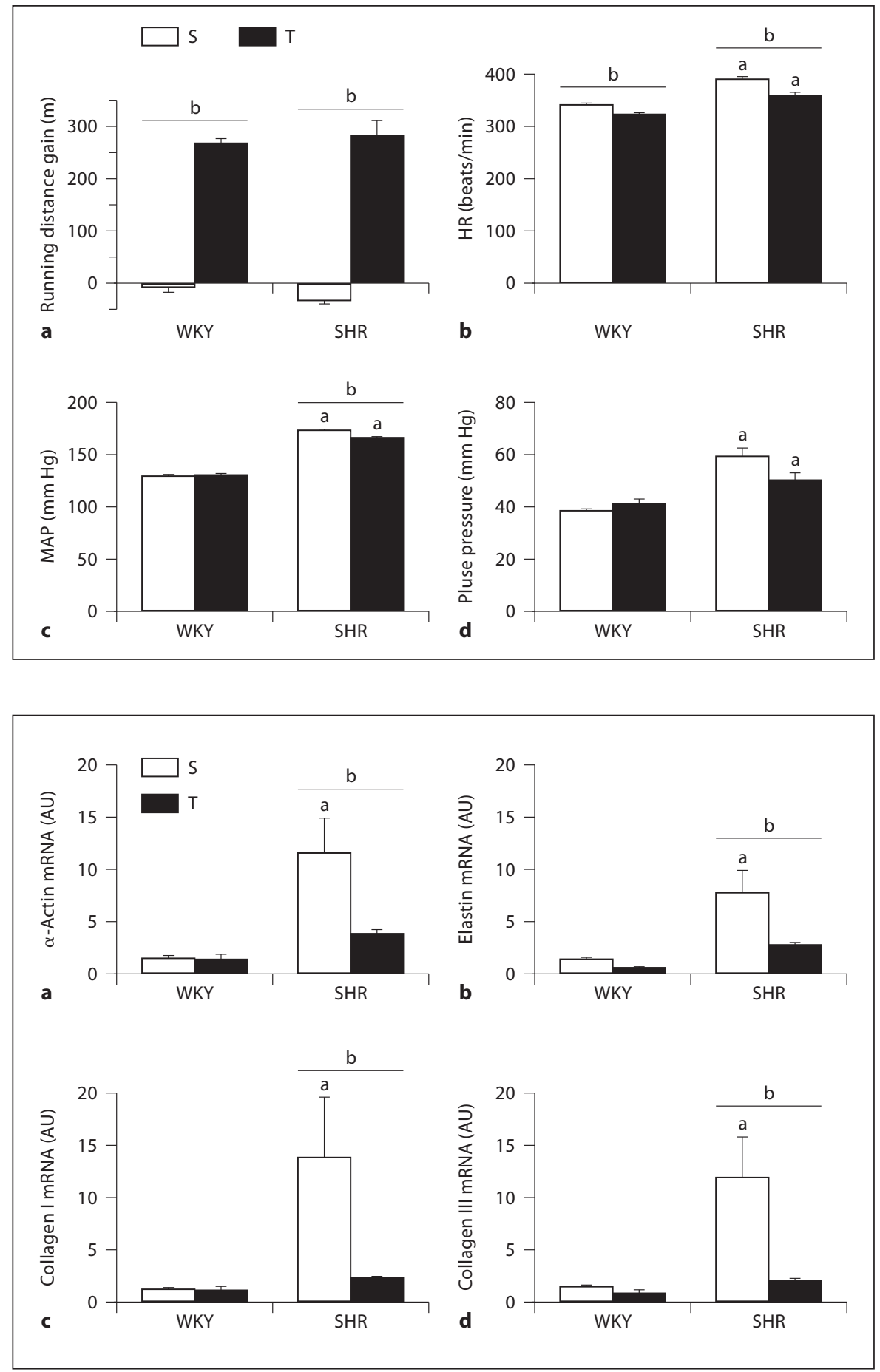

ident and presented a heavy staining, similar to that observed in both WKY groups.

With smaller magnification (figures not shown), one also observed that $\mathrm{SHR}_{\mathrm{S}}$ aortas exhibited a larger outer diameter and cross-sectional area than normotensive controls. Indeed, quantitative measurements (table 1) showed that $\mathrm{SHR}_{\mathrm{S}}$ exhibited a larger outer diameter and cross-sectional area $(+7$ and $+31 \%$, respectively, vs. $\mathrm{WKY}_{S} ; \mathrm{p}<0.05$ ), suggestive of hypertrophic remodelling. Exercise training did not change the cross-section- 

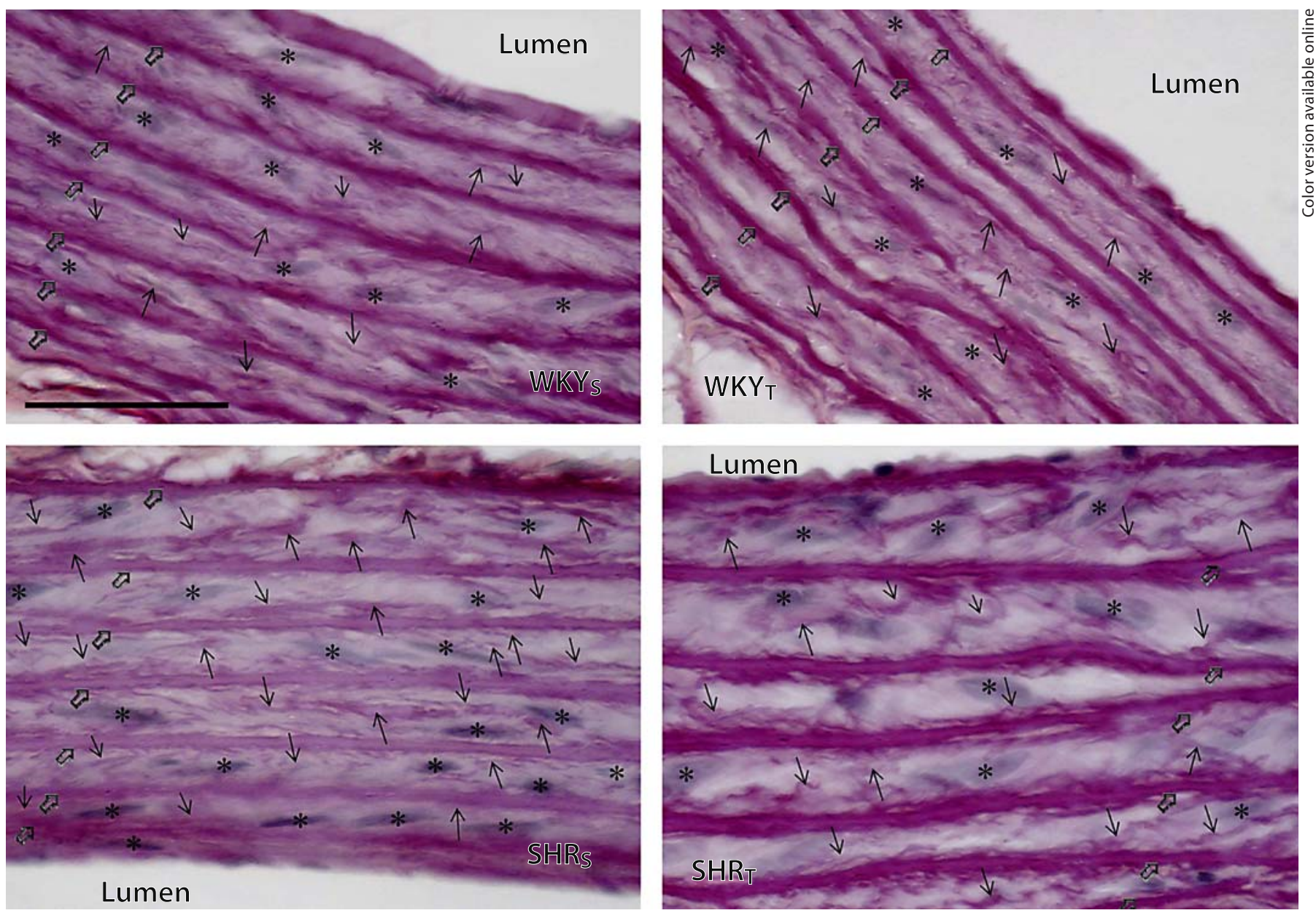

Fig. 3. Light microscope images taken from the thoracic aorta of sedentary and trained normotensive (WKY) and hypertensive (SHR) rats showing elastic lamellas (thick open arrows) and fibrils (thin arrows) stained in purple and smooth muscle cells in rose

with the nucleus stained in pale blue (asterisks). Observe that $\mathrm{SHR}_{\mathrm{S}}$ versus $\mathrm{WKY}_{\mathrm{S}}$ exhibited an increased content of elastic fibres but paler staining - changes that are absent in the $\mathrm{SHR}_{\mathrm{T}}$ group. Scale bar $=100 \mu \mathrm{m}$. The colours refer to the online version.

al area of the SHR group, but caused a slight decrease in the outer diameter (after training, it did not differ from those of the WKY group). No geometric changes were observed in the thoracic aorta of $\mathrm{WKY}_{\mathrm{T}}$ versus $\mathrm{WKY}_{\mathrm{S}}$ (table 1).

Stereological analysis performed on sequential slices revealed that the total volume of the thoracic aorta was higher in the $\mathrm{SHR}_{\mathrm{S}}$ versus the $\mathrm{WKY}_{\mathrm{S}}(\mathrm{p}<0.05$; fig. 4a). $\mathrm{SHR}_{\mathrm{S}}$ aortic smooth muscle cells were bigger, as indicated by their larger volume ( $\mathrm{p}<0.05$ vs. WKY ; fig. $4 \mathrm{c})$. Hypertension was also characterized by significant increases in the elastic components of the aortic wall: from 0.74 \pm 0.32 to $8.69 \pm 0.32 \mathrm{~mm}^{3}$ for the fibrillar component, from $0.65 \pm 0.31$ to $9.02 \pm 0.23 \mathrm{~mm}^{3}$ for the lamellar

component and from $1.38 \pm 0.29$ in the $\mathrm{WKY}_{\mathrm{S}}$ to 14.49 $\pm 0.29 \mathrm{~mm}^{3}$ in the $\mathrm{SHR}_{S}$, corresponding to a 10.5 -fold increase in the total elastic component of the thoracic aorta ( $p<0.05$; fig. $4 \mathrm{~b}$ ). The connective tissue of the aorta, inferred by the difference of the total aortic volume minus the volume of smooth muscle cells plus the total elastic component, was also largely increased in the $\mathrm{SHR}_{S}$ group (+17-fold, $\mathrm{p}<0.05$; fig. $4 \mathrm{~d})$. It is interesting to note that after training the total volume of the thoracic aorta, as well as the volume of smooth muscle, elastic compartments and connective tissue in the $\mathrm{SHR}_{\mathrm{T}}$ group did not differ from those exhibited by the WKY groups (fig. 4). Exercise training had no effects on the stereological properties of the WKY aorta. 
Fig. 4. Estimated total volume $\left(\mathrm{mm}^{3}\right)$ of the thoracic aorta (a) and thoracic aorta wall constituents: elastic fibres (b), smooth muscle (c) and connective tissue (d) of sedentary $(\triangle)$ and trained $(\boldsymbol{\Delta})$ WKY and SHR. Stereological analyses for elastic fibres, smooth muscle and total aortic volume were performed on aortic sequential slices ( 1 section every $25 \mu \mathrm{m}$, extended up to $375 \mu \mathrm{m})$; the volume of the connective tissue was calculated by the difference between the total aortic volume minus the volume of smooth muscle cells + the total elastic component. Triangles indicate individual values and horizontal bars show group means. $\mathrm{n}=7-8$ rats/group. ${ }^{*} \mathrm{p}<$ 0.05 , significant difference when compared to other groups.

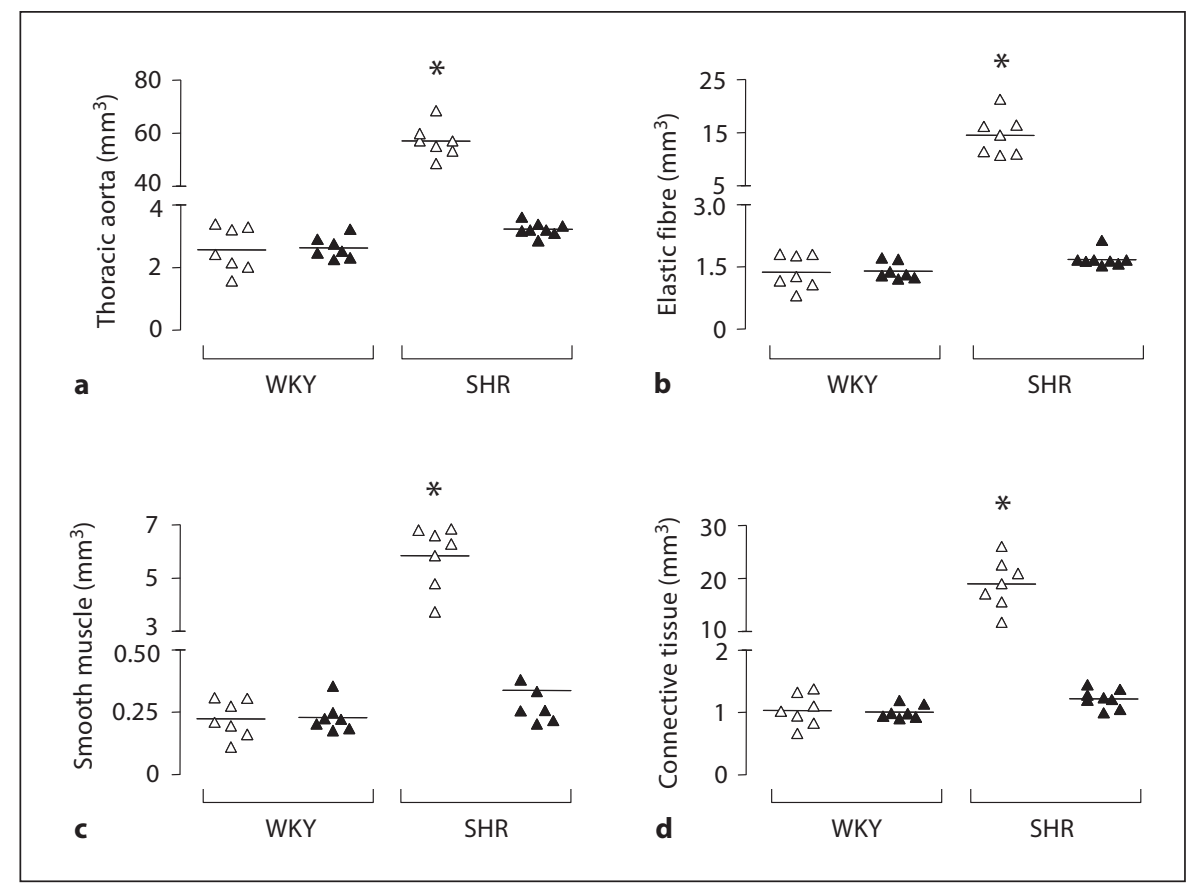

Table 1. Morphometric data of the thoracic aorta in sedentary and trained WKY and SHR rats

\begin{tabular}{|c|c|c|c|c|}
\hline Parameter & $\mathrm{WKY}_{\mathrm{S}}(\mathrm{n}=5)$ & $\mathrm{WKY}_{\mathrm{T}}(\mathrm{n}=5)$ & $\mathrm{SHR}_{\mathrm{S}}(\mathrm{n}=5)$ & $\mathrm{SHR}_{\mathrm{T}}(\mathrm{n}=5)$ \\
\hline $\mathrm{ID}, \mu \mathrm{m}$ & $1,549 \pm 27$ & $1,499 \pm 58$ & $1,639 \pm 34$ & $1,596 \pm 29$ \\
\hline $\mathrm{OD}, \mu \mathrm{m}$ & $1,723 \pm 43$ & $1,691 \pm 70$ & $1,839 \pm 24^{*}$ & $1,803 \pm 27$ \\
\hline Thickness, $\mu \mathrm{m}$ & $96 \pm 14$ & $101 \pm 12$ & $100 \pm 7$ & $103 \pm 4$ \\
\hline Media/lumen ratio & $0.056 \pm 0.005$ & $0.064 \pm 0.009$ & $0.061 \pm 0.005$ & $0.064 \pm 0.003$ \\
\hline $\mathrm{CSA}, \mu \mathrm{m}^{2}$ & $362,948 \pm 14,607$ & $390,182 \pm 22,982$ & $477,752 \pm 20,563^{*}$ & $529,249 \pm 12,589^{*}$ \\
\hline
\end{tabular}

Values are means \pm SEM. ID $=$ Inner diameter; $\mathrm{OD}=$ outer diameter; CSA $=$ cross-sectional area. ${ }^{*} \mathrm{p}<0.05$ versus $\mathrm{WKY}$.

Correlation of Training-Induced Pressure Changes with the mRNA Expression and the Estimated Volume of Aortic Vascular Compartments

In the thoracic aorta of the SHR group, there were positive significant correlations between training-induced pressure fall and either $\alpha$-actin, elastin, collagen I and collagen III mRNA expression ( $\mathrm{p}<0.05$ for all correlations; table 2). Accordingly, training-induced decreases in total aortic volume and in smooth muscle, elastic and connective tissues were positively correlated with a training-induced pressure fall in SHR rats (table 2). No correlations were observed in the WKY group, indicating that training, besides not changing MAP (fig. 1), was unable to change mRNA as well as protein expression in this group.

\section{Effects of Hypertension and Training on the}

Ultrastructure of the Thoracic Aorta

Figure 5 compares ultrastructural pictures of the thoracic aorta of $\mathrm{WKY}_{\mathrm{S}}, \mathrm{WKY}_{\mathrm{T}}, \mathrm{SHR}_{\mathrm{S}}$ and $\mathrm{SHR}_{\mathrm{T}}$, and table 3 summarizes the main qualitative effects of hypertension and training on the ultrastructure of the tunica media and the endothelium observed in several aortic slices taken from 2 rats/group. Both $\mathrm{WKY}_{\mathrm{S}}$ and $\mathrm{SHR}_{\mathrm{S}}$ aortas (fig. 5a, c) showed defective orientation of smooth muscle cells (not parallel to vessel lumen). In addition, larger amounts of collagen and elastin (internal elastic lamina and elastic fibrils) were observed in the $\mathrm{SHR}_{\mathrm{S}}$. In this group, we also observed rupture and duplication of the internal elastic lamina. It is important to 
Table 2. Correlations between mRNA expression with MAP values and between the measured volume of the different vascular components with MAP in WKY and SHR

\begin{tabular}{|c|c|c|}
\hline Correlation & WKY & SHR \\
\hline \multicolumn{3}{|l|}{ mRNA expression, $\mathrm{AU}$} \\
\hline$\alpha$-Actin $\times$ MAP & $\mathrm{Y}=5.9-0.04 \mathrm{x}(\mathrm{r}=-0.163)$ & $Y=-147+0.91 x^{*}(r=0.785)$ \\
\hline Elastin $\times$ MAP & $\mathrm{Y}=7.8-0.05 \mathrm{x}(\mathrm{r}=-0.376)$ & $\mathrm{Y}=-114+0.70 \mathrm{x}^{*}(\mathrm{r}=0.807)$ \\
\hline Collagen $\mathrm{I} \times \mathrm{MAP}$ & $\mathrm{Y}=5.8-0.04 \mathrm{x}(\mathrm{r}=-0.210)$ & $\mathrm{Y}=-157+0.96 \mathrm{x}^{*}(\mathrm{r}=0.738)$ \\
\hline Collagen III $\times$ MAP & $\mathrm{Y}=11.4-0.08 \mathrm{x}(\mathrm{r}=-0.453)$ & $\mathrm{Y}=-214+1.30 \mathrm{x}^{*}(\mathrm{r}=0.815)$ \\
\hline \multicolumn{3}{|l|}{ Measured volume, $\mathrm{mm}^{3}$} \\
\hline Smooth muscle $\times$ MAP & $\mathrm{Y}=-0.19+0.003 \mathrm{x}(\mathrm{r}=0.475)$ & $Y=-50+0.31 x^{*}(r=0.691)$ \\
\hline Total elastic $\times$ MAP & $\mathrm{Y}=-2.52+0.03 \mathrm{x}(\mathrm{r}=0.648)$ & $\mathrm{Y}=-119+0.75 \mathrm{x}^{*}(\mathrm{r}=0.880)$ \\
\hline Connective $\times$ MAP & $\mathrm{Y}=-0.83+0.015 \mathrm{x}(\mathrm{r}=0.385)$ & $Y=-175+1.09 x^{*}(r=0.689)$ \\
\hline Total aortic $\times$ MAP & $\mathrm{Y}=-3.78+0.05 \mathrm{x}(\mathrm{r}=0.516)$ & $\mathrm{Y}=-470+2.95 \mathrm{x}^{*}(\mathrm{r}=0.797)$ \\
\hline
\end{tabular}

Table 3. Main effects of hypertension and training on the ultrastructural characteristics of the thoracic aorta

\begin{tabular}{lll}
\hline & SHR vs. WKY & $\mathrm{SHR}_{\mathrm{T}}$ vs. $\mathrm{SHR}_{\mathrm{S}}$ \\
\hline $\begin{array}{l}\text { Smooth muscle cell } \\
\text { Extracellular matrix } \\
\text { Collagen }\end{array}$ & defective orientation & improved orientation $^{1}$ \\
$\quad \begin{array}{l}\text { Elastin } \\
\text { Elastic fibrils }\end{array}$ & $\downarrow$ content \\
$\quad \begin{array}{l}\text { Internal elastic lamina } \\
\text { Endothelium }\end{array}$ & $\begin{array}{l}\uparrow \text { content } \\
\text { duplication and rupture } \\
\text { involved by collagen }\end{array}$ & $\begin{array}{l}\downarrow \text { content } \\
\text { prevention of both } \\
\downarrow \text { collagen content }\end{array}$ \\
\hline
\end{tabular}

Observations made in 15 slices/thoracic aorta (2 rats/group).

${ }^{1}$ Improved orientation was also observed in $\mathrm{WKY}_{\mathrm{T}}$ versus $\mathrm{WKY}$.

note that training in both groups caused a marked reorganization of the smooth muscle cells: they presented a more elongated shape and are disposed preferentially along the circumferential axis of the vessel, an anatomical organization that reminds us of the contractile phenotype of the cell (fig. 5b, d; table 3). In the SHR group, training also decreased the number of elastic fibrils, prevented both rupture and duplication of the internal elastic lamina and reduced the collagen contend both in the tunica media and around the endothelium (fig. 5c, d; table 3). With the exception of the reorganization of smooth muscle cells, training caused minor changes in the extracellular matrix components of the aorta in the WKY group.

\section{Discussion}

The main findings of this study were: (1) aerobic training caused minor changes in the thoracic aorta macrostructure but was vastly effective to reduce elastin mRNA expression and to normalize the increased elastic content of the SHR aortas; (2) exercise training normalized $\alpha$ actin expression and the total volume of smooth muscle cells, improving its circumferential orientation within the wall; (3) similar to other antihypertensive therapies, exercise training also reduced collagen mRNA expression and the connective tissue content in the thoracic aorta, thus reducing fibrosis; (4) these changes slightly decreased the pulsatility of $\mathrm{SHR}_{\mathrm{T}}$ aortas and were positively 

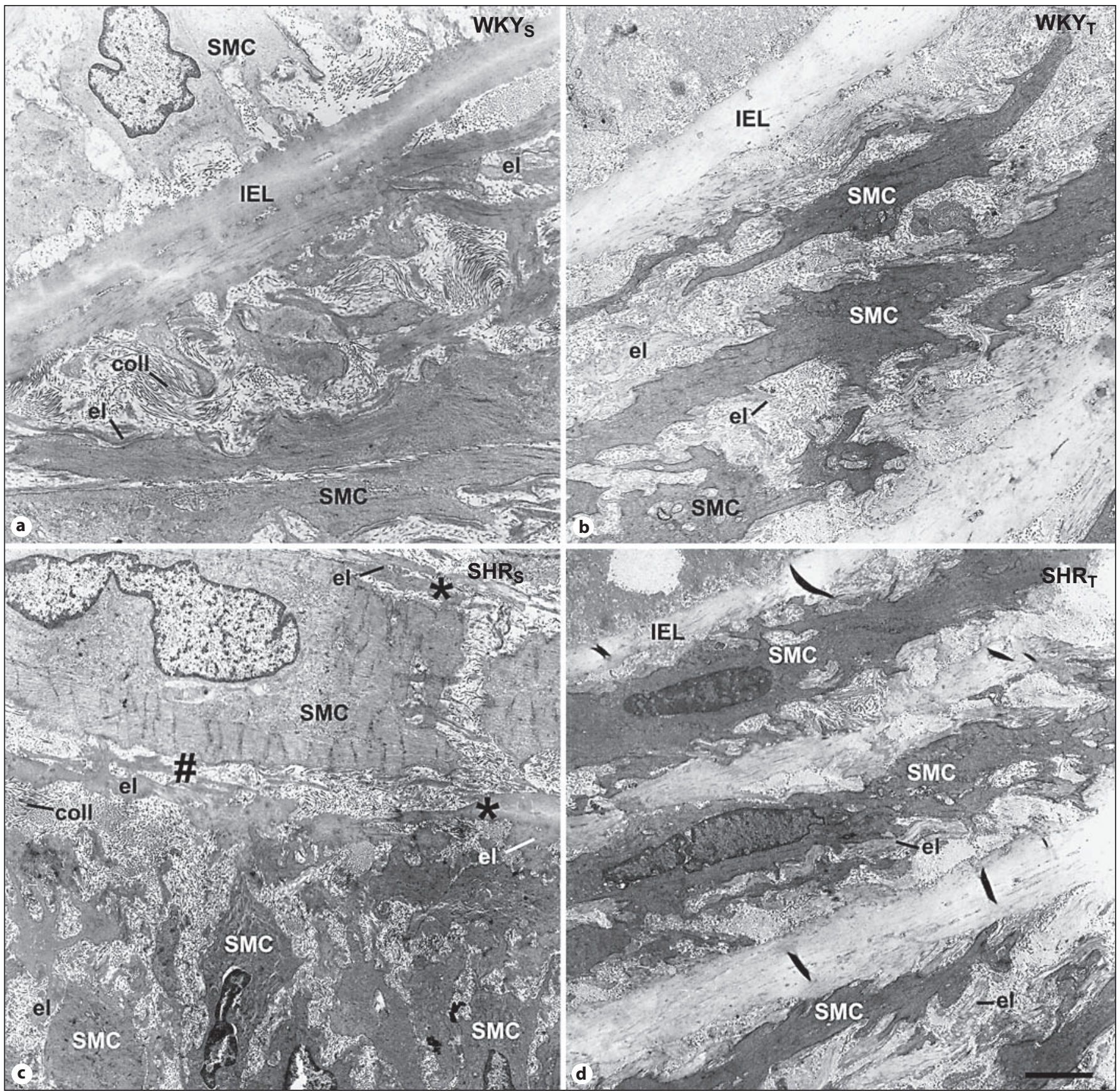

Fig. 5. Transmission electron microscopy images depicting the intima and part of media layers of the thoracic aorta in sedentary $(\mathbf{a}, \mathbf{c})$ and trained $(\mathbf{b}, \mathbf{d}) \mathrm{WKY}(\mathbf{a}, \mathbf{b})$ and SHR $(\mathbf{c}, \mathbf{d})$. Observe the rupture (\#) and duplication $\left(^{*}\right)$ of the internal elastic lamina (IEL) in the $\mathrm{SHR}_{\mathrm{S}}$, the defective orientation of smooth muscle cells (SMC) in the sedentary groups changed to circumferential orientation after training and the relative contents of elastin (el) and collagen (coll). Scale bar $=2 \mu \mathrm{m}$. 
correlated to training-induced pressure fall, and (5) besides a similar increase in performance gain and the appearance of resting bradycardia (a marker for training), exercise training did not change pressure, mRNA expression and the volume of any aortic wall constituent in the WKY group.

Previous studies had already shown that hypertension is associated with structural and mechanical alterations in conduit arteries such as wall hypertrophy and/or remodelling, due to changes in the proliferation rate of smooth muscle cells and in the pattern of extracellular matrix synthesis $[3-5,26,27]$. Indeed, an imbalance between cell growth/death and excessive collagen and elastin synthesis are characteristic markers of hypertensive vascular remodelling. Under normal conditions, elastic fibres, the main constituent of the thoracic aorta, have a short period of active synthesis, restricted to foetal life and the neonatal period [28]. However, in the presence of increased mechanical stress and other neurohormonal factors imposed by hypertension, defective elastin synthesis is activated, generating stiffer macropolymers (with smaller fenestrae in the elastic lamellae) that exhibit a very low turnover $[3,29]$. The present set of data confirmed aortic wall hypertrophy (significant increase in both $\alpha$-actin mRNA expression and total volume of aortic smooth muscle, accompanied by augmented outer diameter and cross-sectional area), increased collagen I and collagen III mRNA expression and augmented connective tissue with a high content of collagen fibres (qualitative ultrastructural evaluation) in the thoracic aorta of the $\mathrm{SHR}_{\mathrm{s}}$. In addition, data showed increased systolic and pulse pressure accompanied by both a marked increase in elastin mRNA expression and robust increase in total elastic component (high content of defective elastic lamellas/fibres, exhibiting ruptures and duplications of the internal elastic lamina, as revealed by qualitative ultrastructural analysis). Indeed, in hypertensive and elder individuals, it has been shown that elastic fibres break down due to augmented circumferential wall stress $[3,30]$. It should be noted that not only the augmented collagen content but also the abnormal deposit of elastin are deleterious for the mechanical properties of the aortic wall $[3-5,7,8,29,31]$. The loss of aortic mechanical performance causes vessel stiffening, endothelial damage and deficient physical barrier for cellular migration with increased local inflammatory responses [26, 27, 32, 33].

Previous studies evaluating the effect of pressure fall on media composition, morphology and function of conductance/resistance arteries in hypertensive patients and animals have already shown the ability of antihyperten- sive therapies in reducing pulse wave velocity and the carotid augmentation index [15], in decreasing either media cross-sectional area, collagen volume density and collagen/elastin ratio $[6,8,12,14]$, but no correction of the elastic component has been observed with the pharmacological therapies used so far $[6,11,13,14]$. Interestingly, lowintensity aerobic training, while contributing to blood pressure reduction, was very effective to correct both aortic hypertrophy and extracellular matrix composition (decreased collagen and elastin message and content), as well as to prevent a breakdown of the internal elastic lamina, thus reducing defective changes in the $\mathrm{SHR}_{\mathrm{T}}$. This is a novel benefit of training in hypertensive individuals. The mechanisms by which exercise training decreases elastin synthesis, reduces elastic content and avoids fibre ruptures/duplications are unknown at the present. Exercise-induced antioxidative capacity was shown to contribute to protective effects in the aortic wall of $\mathrm{SHR}_{\mathrm{T}}$ [34]. Elements of the cytoskeleton could participate in the perception/transduction of the altered stress since colchicine administration during the development of renal and/or Dahl-sensitive hypertension abolished the vascular hypertrophic response while it affected pressure rise only marginally [8]. The availability of angiotensin II may also contribute to changing the elastin content since SHR treated with enalapril exhibited a significant reduction in the collagen/elastin ratio [13]. In addition, young normotensive animals treated with enalapril showed a marked decrease in accumulation of total elastin in the aorta [35]. It has also been shown that converting enzyme inhibitors, as well as angiotensin receptor blockers, reduced the collagen/elastin ratio in treated SHR while attenuating the expression of integrin in the arteries [12, 14, 36]. Indeed, exercise training by reducing either the activity of the renin-angiotensin system $[37,38]$, mean pressure and pulsatility (present set of data) was able to decrease aortic stress and the stress-sensing mechanism. Future experiments might explore these possibilities.

Besides the reduced synthesis of extracellular matrix induced by exercise training, smaller accumulation of the elastic component in the aor tic wall of $\mathrm{SHR}_{\mathrm{T}}$ could be due to an accelerate breakdown of elastic (and collagen) fibres. Possible mechanisms conditioning the increased turnover of extracellular matrix proteins remain to be determined.

It is important to note that training in SHR has direct effects on extracellular matrix remodelling (reduced content of both elastic and collagen fibres) and smooth muscle normalization (reduced $\alpha$-actin expression and media smooth muscle content with improved orientation of 
smooth muscle cells), determining a noticeable reduction in pulse pressure. Although the $16 \%$ decrease in the pulse pressure of $\mathrm{SHR}_{\mathrm{T}}$ (measured at the carotid artery, not the true calculation of the central aortic or augmented pressure) did not reach significance, it indicates a slight decrease in aortic pulsatility. These changes improved buffering function of the aorta in the $\mathrm{SHR}_{\mathrm{T}}$. In addition, the expression of $\alpha$-actin and extracellular matrix proteins as well as muscle volume, elastic and connective components of the aorta were positively correlated with MAP levels, suggesting that training-induced reduction in mRNA and protein content are related to training-induced pressure fall. Exercise training also has a direct effect on the heart (reduced HR). Establishment of training-induced resting bradycardia, mediated by central oxytocinergic and renin-angiotensin system adjustments $[20,38]$, together with outward eutrophic remodelling in exercised SHR arterioles $[17,18]$ and capillary angiogenesis [39-41] are important factors to reduce haemodynamic stress. The direct effects of exercise training, by changing wall composition, improving aortic cushioning function and reducing haemodynamic stress, were additive to cause a significant pressure fall in the $\mathrm{SHR}_{\mathrm{T}}$.

It should be stressed that with the exception of improved orientation of aortic smooth muscle cells, training-induced benefits on the vascular wall were only ap- parent in the SHR rats since no effects were observed in the WKY group submitted to the same training protocol. This observation is in accordance with our previous studies showing the efficacy of exercise training to correct cardiovascular disarrangements only in hypertensive individuals [17, 18, 20, 39-41].

In conclusion, exercise training caused only minor changes in the aortic macrostructure, but proved to be a very effective tool to normalize the increased elastic content in the SHR aortas, in addition to the reduced collagen/connective tissue content and to the reduced smooth muscle cell volume observed in the $\mathrm{SHR}_{\mathrm{T}}$. These adaptive structural responses occurring simultaneously with training-induced pressure fall, a slight decrease in aortic pulsatility and resting bradycardia, reduce aortic stiffness, thus facilitating the buffering function and reduction in cardiovascular risk.

\section{Acknowledgments}

This study was supported by Fundação de Amparo à Pesquisa do Estado de São Paulo (FAPESP 06/50548-9 and 08/53961-0), Coordenação de Aperfeiçoamento de Pessoal de Nível Superior - CAPES (fellowship to M.T.J.) and Conselho Nacional de Desenvolvimento Científico e Tecnológico (CNPq). L.C.M. is a Research Fellow of CNPq.

\section{References}

1 Nichols WW, O'Rourke M: McDonald's Blood Flow in Arteries: Theoretical, Experimental and Clinical Principles, ed 4. London, Arnold, 1998, pp 54-401.

-2 Safar ME, Levi BI, Struijker-Boudier H: Current perspectives on arterial stiffness and pulse pressure in hypertension and cardiovascular diseases. Circulation 2003;107: 2864-2869.

-3 Arribas SM, Hinek A, González MC: Elastic fibers and vascular structure in hypertension. Pharmacol Ther 2006;111:771-791.

-4 Chamiot CP, Renaud JF, Blacher J, Legrand M, Samuel JL, Levy BI, Sassard J, Safar ME: Collagen I and III and mechanical properties of conduit arteries in rats with genetic hypertension. J Vasc Res 1999;36:139-146.

- 5 Olsen MH, Christensen MK, Wachtell K, Tuxen C, Fossum E, Bang LE, Wiinberg N, Devereux RB, Kjeldsen SE, Hildebrandt P, Dige-Petersen H, Rokkedal J, Ibsen H: Markers of collagen synthesis is related to blood pressure and vascular hypertrophy: a LIFE substudy. J Hum Hypertens 2005;19:301307.
6 Han WQ, Wu LY, Zhou HY, Zhang J, Che ZQ, Wu YJ, Liu JJ, Zhu DL, Gao PJ: Changes in the composition on the thoracic aortic wall in spontaneously hypertensive rats treated with losartan or spironolactone. Clin Exp Pharmacol Physiol 2009;36:583-588.

7 Keeley FW, Johnson DJ: The effect of developing hypertension on the synthesis and accumulation of elastin in the aorta of the rat. Biochem Cell Biol 1986;64:38-43.

8 Keeley FW, Alatawi A: Response of aortic elastin synthesis and accumulation to developing hypertension and the inhibitory effect of colchicine on this response. Lab Invest 1991;64:499-507.

-9 Jacob MP: Extracellular matrix remodeling and matrix metalloproteinases in the vascular wall during ageing and in pathological conditions. Biomed Pharmacol 2003;57:195-200.

10 Keeley FW, Bartoszewicz LA: Elastin in systemic and pulmonary hypertension. Ciba Found Symp 1995;192:259-278.
11 Keeley FW, Elmoslhi A, Leenen FH: Effects of antihypertensive drug classes on regression of connective tissue components of hypertension. J Cardiovasc Pharmacol 1991; 17:S64-S69.

12 Schiffrin EL: Remodeling of resistance arteries in essential hypertension and effects of antihypertensive treatment. Am J Hypertens 2004;17:1192-1200.

13 Sharifi AM, Li JS, Endemann D, Schiffrin EL: Effects of enalapril and amlodipine on smallartery structure and composition, and on endothelial dysfunction in spontaneously hypertensive rats. Hypertension 1998;16:457-466.

14 Intengan HD, Thibault G, Li JS, Schiffrin EL: Resistance artery mechanics, structure, and extracellular components in spontaneously hypertensive rats - effects of angiotensin receptor antagonism and converting enzyme inhibition. Circulation 1999;100:2267-2275.

15 Vaitkevicious PV, Fleg JL, Engel JH, O'Connor FC, Wright JG, Lakatta LE, Yin FCP: Effects of age and aerobic capacity on arterial stiffness in healthy adults. Circulation 1993;88:1456-1462. 
-16 Tanaka H, Safar ME: Influence of lifestyle modification on arterial stiffness and wave reflections. Am J Hypertens 2005;18:137144.

-17 Amaral SL, Zorn TMT, Michelini LC: Exercise training normalizes wall-to-lumen ratio of the gracilis muscle arterioles and reduces pressure in spontaneously hypertensive rats. J Hypertens 2000;18:1563-1572.

-18 Melo RM, Júnior EM, Michelini LC: Training-induced, pressure-lowering effect in SHR - wide effects on circulatory profile of exercised and nonexercised muscle. Hypertension 2003;42:851-857.

19 Braga DC, Mori E, Higa KT, Morris M, Michelini LC: Central oxytocin modulates exercise-induced tachycardia. Am J Physiol Regul Integr Comp Physiol 2000;6:14741482 .

-20 Martins AS, Crescenzi A, Stern JE, Bordin S, Michelini LC: Hypertension and exercise training differentially affect oxytocin and oxytocin receptor expression in the brain. Hypertension 2005;45:1004-1009.

-21 Higa-Taniguchi KT, Silva FC, Silva HM, Michelini LC, Stern JE: Exercise training-induced remodeling of paraventricular nucleus (nor)adrenergic innervation in normotensive and hypertensive rats. Am J Physiol Regul Integr Comp Physiol 2007;292:17171727.

-22 Pfaffl MW: A new mathematical model for relative quantification in real-time RT-PCR Nucleic Acid Res 2001;29:e45.

$\checkmark 23$ Gundersen HJG, Jensen EB, Kiê UK, Nielsen $\mathrm{J}$ : The efficiency of systematic sampling in stereology: reconsidered. J Microsc 1999; 193:199-211.

24 Howard CV, Reed MG: Unbiased Stereology. Three-Dimensional Measurement in Microscopy. Oxford, Bios Scientific Publishers, 2005.
25 Lima AR, Nyengaard JR, Jorge AA, Balieiro JC, Peixoto C, Fioretto ET, Ambrósio CE, Miglino MA, Zatz M, Ribeiro AA: Muscular dystrophy-related quantitative and chemical changes in adenohypophysis GH-cells in Golden Retrievers. Growth Horm IGF Res 2007;17:480-491.

26 Intengan HD, Schiffrin EL: Vascular remodeling in hypertension. Roles of apoptosis, inflammation, and fibrosis. Hypertension 2001;38:581-587.

27 Owens GK, Kumar MS, Wamhoff BR: Molecular regulation of vascular smooth muscle cell differentiation in development and disease. Physiol Rev 2004;84:767-801.

28 Iredale RB, Eccleston-Joyner CA, Rucker RB, Gray SD: Ontogenic development of the elastic component of the aortic wall in spontaneously hypertensive rats. Clin Exp Hypertens 1989;11:173-187.

29 Arribas SM, Briones AM, Bellingham C, González MC, Salaices M, Liu K, Wang Y, Hinek A: Heightened aberrant deposition of hard-wearing elastin in conduit arteries of prehypertensive SHR is associated with increased stiffness and inward remodeling. Am J Physiol Heart Circ Physiol 2008, 295:H2299-H2307.

30 Nichols WW: Clinical measurement of arterial stiffness obtained from noninvasive pressure waveforms. Am J Hypertens 2005; $18: 3 S-10 S$.

31 Weissen-Plenz G, Sindermann JR: Loking for molecular mechanisms underlying aberrant elastin deposition in hypertension. Am J Physiol Heart Circ Physiol 2008;296:H900.

-32 Yasmin SW, McEniery CM, Dakham Z, Pusalkar P, Maki-Petaja K, Ashby MJ, Cockcroft JR, Wilkinson IB: Matrix metalloproteinase-9 (MMP-9), MMP-2, and serum elastase activity are associated with systolic hypertension and arterial stiffness. Arterioscler Thromb Vasc Biol 2005;25:372-378.

-33 Martinez-Lemus LA, Hill MA, Meininger GA: The plastic nature of vascular wall: a continuum of remodeling events contributing to control of arteriolar diameter and structure. Physiology 2009;24:45-57.
>34 Hägg U, Andersson I, Naylor AS, Grönros J, Jonsdittir IH, Bergström G, Gan L: Voluntary physical exercise-induced vascular effects in spontaneously hypertensive rats. Clin Sci 2004;107:571-581.

35 Keeley FW, Elmoslhi A, Leenen FH: Enalapril suppresses normal accumulation of elastin and collagen in cardiovascular tissues of growing rats. Am J Physiol 1992;262:H1013H1021.

-36 Touyz RM: The role of angiotensin II in regulating vascular structural and functional changes in hypertension. Curr Hypertens Rep 2003;5:155-164.

>37 Klett CPR, Anderson D, Sholook M, Granger JP: Antisense oligodeoxynucleotides directed against a novel angiotensinogen mRNA stabilizing protein reduce blood pressure in spontaneously hypertensive rats. Am J Physiol Regul Integr Comp Physiol 2004; 287:R619-R626.

38 Felix JVC, Michelini LC: Training-induced pressure fall in spontaneously hypertensive rats is associated with reduced angiotensiogen mRNA expression within the nucleus tractus solitari. Hypertension 2007;50:780-785.

>39 Amaral SL, Silveira NP, Zorn TMT, Michelini LC: Exercise training causes skeletal muscle venular growth and alters hemodynamic responses in spontaneously hypertensive rats. J Hypertens 2001;19:931-940.

40 Amaral SL, Sanchez LS, Chang AJ, Rossoni LV, Michelini LC: Time course of traininginduced microcirculatory changes and of VEGF expression in skeletal muscles of spontaneously hypertensive female rats. Braz J Med Biol Res 2008;41:424-431.

-41 Coimbra R, Sanchez LS, Potenza JM, Rossoni LV, Amaral SL, Michelini LC: Is gender crucial for cardiovascular adjustments induced by exercise training in female spontaneously hypertensive rats? Hypertension 2008;52:514-521. 